\title{
BMJ
}

\section{Competing risks of mortality with marathons: retrospective analysis}

\author{
Donald A Redelmeier, professor of medicine, , J Ari Greenwald, resident in emergency medicine ${ }^{2}$
}

1Department of Medicine,

University of Toronto, and

Sunnybrook Health Sciences

Centre, Ontario, Canada M4N 3M5

${ }^{2}$ Department of Medicine,

University of Toronto, Toronto,

Canada

Correspondence to: DA Redelmeier

dar@ices.on.ca

doi:10.1136/bmj.39384.551539.25

\section{ABSTRACT}

Objective To determine from a societal perspective the risk of sudden cardiac death associated with running in an organised marathon compared with the risk of dying from a motor vehicle crash that might otherwise have taken place if the roads had not been closed.

Design Population based retrospective analysis with linked ecological comparisons of sudden death.

Setting Marathons with at least 1000 participants that had two decades of history and were on public roads in the United States, 1975-2004.

Main outcome measures Sudden death attributed to cardiac causes or to motor vehicle trauma.

Results The marathons provided results for 3292268 runners on 750 separate days encompassing about 14 million hours of exercise. There were 26 sudden cardiac deaths observed, equivalent to a rate of 0.8 per 100000 participants ( $95 \%$ confidence interval 0.5 to 1.1). Because of road closure, an estimated 46 motor vehicle fatalities were prevented, equivalent to a relative risk reduction of $35 \%$ (95\% confidence interval $17 \%$ to $49 \%$ ). The net reduction in sudden death during marathons amounted to a ratio of about 1.8 crash deaths saved for each case of sudden cardiac death observed $(95 \%$ confidence interval: 0.7 to 3.8). The net reduction in total deaths could not be explained by re-routing traffic to other regions or days and was consistent across different parts of the country, decades of the century, seasons of the year, days of the week, degree of competition, and course difficulty. Conclusion Organised marathons are not associated with an increase in sudden deaths from a societal perspective, contrary to anecdotal impressions fostered by news media.

\section{INTRODUCTION}

Physicians often recommend the health benefits of exercise, and millions of people take part on a regular basis, yet the outcome for a few participants is sudden death. These fatalities are typically diagnosed as "sudden cardiac death" and research has found no ideal method for predicting such events as even people without symptoms can be susceptible. ${ }^{1-3}$ The deaths are poignant because the risk is voluntary, the outcome is catastrophic, and the person might otherwise have lived a long life. ${ }^{4-6}$ The deaths also attract repetitive media attention, such as the high publicity given to deaths that occur in marathon runners. ${ }^{7-11}$ As a consequence, the deaths undercut support for such community events, invite more screening of potential participants, and decrease public enthusiasm for aerobic exercise. ${ }^{12-17}$

Motor vehicle crashes are also hard to predict and are potentially fatal. In the United States, for example, 42643 individuals died in motor vehicle crashes over the $6354190 \mathrm{~km}$ of public roads during 2003 (equal to about 12 deaths per $42 \mathrm{~km}$ (26.2 miles, the length of a marathon) of road per 1000 hours). ${ }^{18}$ In contrast with sporting event fatalities, these deaths occur more than a hundred times each day and tend to be under-reported in the media. ${ }^{1920}$ The death statistics, furthermore, understate the full extent of consequences given the additional number of crashes that cause permanent disability. Ironically, deaths from motor vehicle crashes often lead to little public outcry or alterations in the behaviour of individuals in the community. ${ }^{21}$ This competing risk of harm is rarely considered in the analysis of events related to exercise. ${ }^{22}$

No previous study has explored the extent to which marathons might actually decrease mortality. Our core theory was that the number of deaths attributed to running a marathon might be smaller than the number of deaths averted by the reductions in road crashes that would otherwise have occurred. We anticipated that such net benefits would be confined to the marathon route and would not be evident elsewhere in the state. To test this theory we examined marathons throughout the US for a population based test of whether the total number of sudden deaths (cardiac or crash related) changed when roads are closed to traffic and opened to marathon running from the perspective of society.

\section{METHODS}

\section{Marathon identification}

We screened the 328 marathons listed in the Runner's World registry on 1 January 2005 (chosen because the source is a leading publication in the field, is updated continually, and undergoes extensive public scrutiny). We randomly selected 26 marathons to provide a diverse national sample and followed each for up to 30 years. All included marathons were in the US and provided background material on their history. We excluded marathons with fewer than 20 years of 


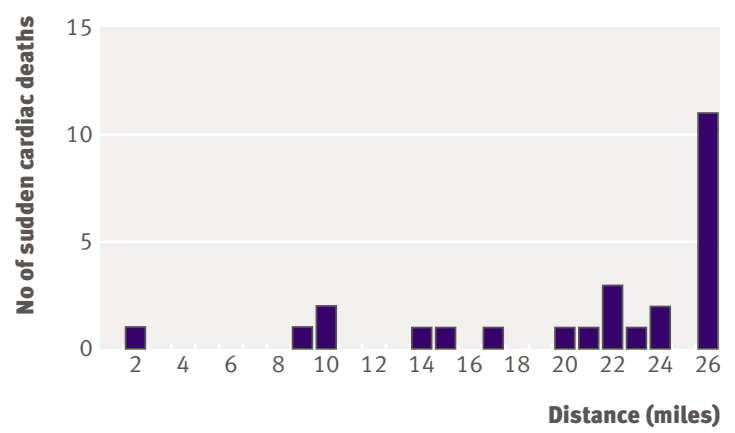

Fig 1 Distribution of sudden cardiac deaths according to distance along marathon course when participant collapsed (to nearest mile; 1 mile=1.6 km; total course 26.2 miles, equal to $42 \mathrm{~km}$ ). Deaths expressed as counts summed over all marathons and years

experience or fewer than 1000 participants annually to ensure sufficient data for statistical testing of infrequent events. We also excluded marathons located primarily on off-road trails or that were part of a larger endurance event (for example, Ironman). Dates and routes of specific marathons were obtained from dedicated websites, regional periodicals, selected race directors, running clubs, local sportscasters, and national running organisations.

\section{Cardiac fatalities}

We obtained data on sudden cardiac deaths from local newspapers on the days after each marathon. Such fatalities are dramatic in nature, occur in public view, and are of intense interest in the press. For the Boston marathon, the sources were the Boston Globe and the Boston Herald. Similarly, reports for other marathons were obtained by identifying the newspaper with the widest local circulation and selecting the three issues published after the event. In cases where local newspapers provided no mention of the marathon, we searched other newspapers and periodicals for three issues until we found a review. Data on specific cause of death required up to four months of follow-up. Searches for missing data were validated by contact with race directors or local news media. We did not study suicide or violent crime because we had no compelling basis for an association between these causes of sudden death and a local marathon.

\section{Crash fatalities}

We retrieved road safety information for the US from the National Highway Traffic Safety Administration (NHTSA). This provided population based data for all fatal crashes on public roads starting from 1975 and continuing uninterrupted with a one to two year lag in reporting. As in past research, ${ }^{23}$ we identified each person who died in a fatal crash and compared the number observed during a marathon with the number expected based on the same day one week before and one week after. This technique controlled for season of the year, day of the week, and year of the century and indirectly controlled for confounders such as vehicle technology, roadway layout, safety equipment, and drivers' skill. In all analyses we distinguished counties in the state that were inside and outside the marathon course and hours that were inside and outside the general interval of related road closures. The same locations and clock times were used for all comparisons to ensure identical intervals for all analyses.

\section{National analyses}

We compiled all marathons together into a central database taking into account the day of each marathon, along with the counties and state in which it was run. The location of each marathon was characterised according to state counties because the NHTSA database did not code crash location beyond this degree of precision. The time of each marathon was defined according to the approximate interval of road preparation, closure, clean up, and congestion as 3 am to $3 \mathrm{pm}$ because archival data on exact times were unavailable in early eras for most marathons. The size of each marathon was estimated from the number of finishers in each year and course, with missing reports estimated by interpolation where possible or by replacement with zero otherwise (so that estimates of cardiac risk were biased upwards). Information on record times and cash prizes was obtained directly from the individual organisations based on the most recent data available.

\section{Statistical analysis}

Our primary analysis identified the number of motor vehicle deaths during each marathon compared with the number during the same hours one week before and one week after for the counties involving the marathon route (for example, a Sunday marathon in Chicago was compared with the Sunday before and the Sunday after in Chicago). Summary statistics were based on binomial tests and not adjusted for clustering. ${ }^{24}$ The same comparisons were then replicated for state counties that were outside the marathon route to check for spillover in traffic flow to surrounding regions. Secondary analyses also checked for spillover in traffic flow by examining the days immediately before and after each marathon for counties inside the marathon route. Analyses of cardiac deaths during each marathon were expressed with exact confidence intervals and assumed that no cardiac deaths would have occurred otherwise (to ensure that estimates of cardiac risk were not biased downwards). Power calculations were not conducted. Further details are available directly from the authors.

\section{RESULTS}

The 26 marathons over the 30 years provided results for 2250 separate days of observation (750 marathon days and 1500 control days). Collectively, this amounted to 3292268 participants each running 42 $\mathrm{km}$ (26.2 miles). Over the 30 years there were 26 sudden cardiac deaths. Fifteen marathons had no deaths, six had one, and five had more than one (Boston, New York, Chicago, Honolulu, Washington 
Marine Corps). One marathon had more than one death in a single year (New York with two deaths in 1994). No major trend in cardiac deaths was observed over the years.

The typical participant with sudden cardiac death was a middle aged adult man (average age 41 years, $81 \%$ men). Five deaths occurred in individuals who had previously completed a marathon. Autopsy results were available for 24 , the most common finding being coronary atherosclerosis $(n=21)$. Other contributing factors in scattered cases included electrolyte abnormalities $(n=4)$, coronary anomalies $(n=2)$, and heat stroke $(n=1)$. The most common course location of cardiac death was at or within $1.6 \mathrm{~km}$ (1 mile) of the finish line (fig 1).

The overall risk of sudden cardiac death was equal to 0.8 per 100000 participants (95\% confidence interval 0.5 to 1.1). This was equivalent to about three deaths per $42 \mathrm{~km}$ of roadway per 1000 hours. No individual marathon course had an observed risk of sudden cardiac death that was significantly higher or lower than this baseline risk. The risk of sudden cardiac death was collectively distributed over about 86 million total miles of running by participants and mathematically equal to about two deaths per million hours of exercise.

Over the 30 years a total of 12364 motor vehicle fatalities occurred on the 750 marathon days and 1500 control days in the corresponding states. A minority $(n=930)$ were in counties inside the course whereas most $(n=11434)$ were in counties outside the course. The typical person who died in a fatal crash was a middle aged adult man (mean age 38 years, $78 \%$ men). About 56\% were drivers, $25 \%$ were passengers, and $19 \%$ were pedestrians or other vulnerable road users. Marathon courses varied markedly around the prevailing average with no systematic week to week trend in crash deaths.

A total of 85 individuals died in fatal crashes on the marathon days in counties inside the course during hours when roads were closed. In contrast, 262 individuals died in fatal crashes on the control days in the corresponding counties and hours. Given that each marathon was paired with two control days, the discrepancy between observed and expected crash deaths on marathon days corresponded to a $35 \%$ relative decrease in risk (17\% to $49 \%)$. This discrepancy was equal to an absolute decrease of 46 total crash deaths over the study $(\mathrm{P}<0.001)$.

We observed no major spillover in crash deaths to surrounding regions attributable to re-routing of traffic. Analysis of counties outside the course that compared observed with expected crash deaths during hours of road closure showed no countervailing increase in fatal crashes (relative decrease $0 \%,-6 \%$ to $7 \%$ ). This discrepancy was equal to an absolute decrease of five deaths $(\mathrm{P}>0.20)$. Inspection of scatter plots showed no major departures from the general pattern of decreased crash deaths inside the marathon course and no increase in crash deaths outside the marathon course (fig 2).
Secondary analyses also showed no spillover in crash deaths to days surrounding the marathon for the counties involved in the road closures. Focusing on the three days before the marathon during the corresponding hours, we observed no significant increase in risk (relative increase in deaths $3 \%$, absolute increase in deaths $9, \mathrm{P}>0.20)$. Focusing on the three days after the marathon during the corresponding hours, we observed no significant increase in risk (relative decrease in deaths $4 \%$, absolute decrease in deaths $11, \mathrm{P}>0.20)$.

The ratio of crash deaths prevented was about 1.8 for each case of sudden cardiac death attributed to the marathon (95\% confidence interval 0.7 to 3.8$)$. The reduced risk of sudden death was consistent across different regions of the country, decades of the century, seasons of the year, days of the week, degree of competition (as measured by prize money), and course difficulty (as measured by winning race time). Each subgroup showed a protective association, though confidence intervals were wide in all cases (fig 3).

\section{DISCUSSION}

In this study of more than three million marathon runners over 30 years the risk of sudden cardiac death was small, occurring at a frequency of 0.8 for every 100000 participants. This is equivalent to about two deaths per million hours of vigorous exercise. For each person who died from sudden cardiac death, we estimated a ratio of almost two lives saved from fatal
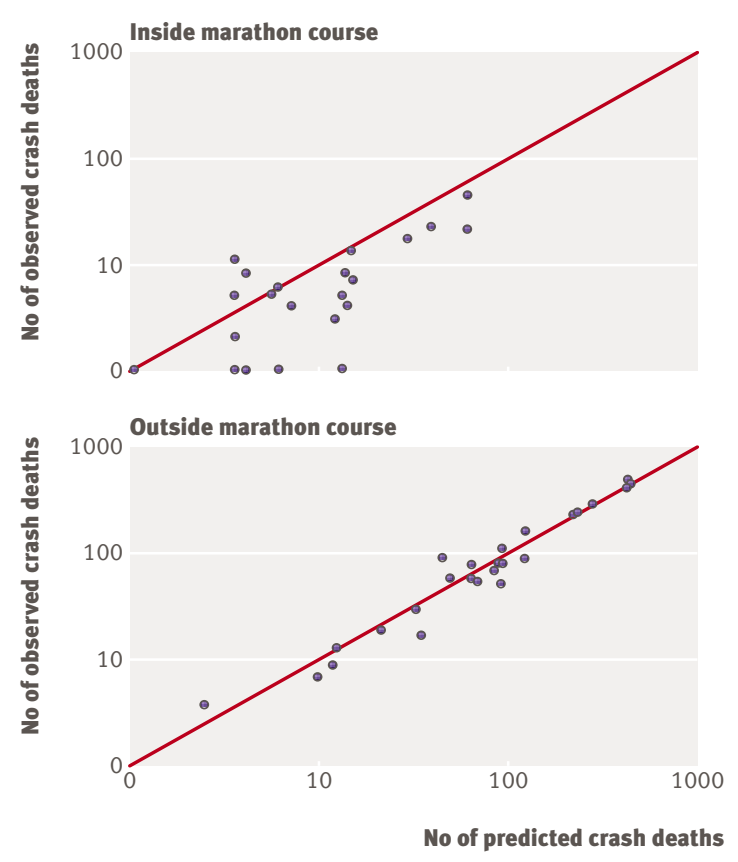

Fig 2 Comparison of observed crash fatalities on marathon days relative to predicted crash fatalities on control days. Top: counties inside marathon route; bottom: counties outside marathon route and data from corresponding hours of road closures. Each point represents one marathon site summed over all years. Note logarithmic scale and zero values plotted at 1 


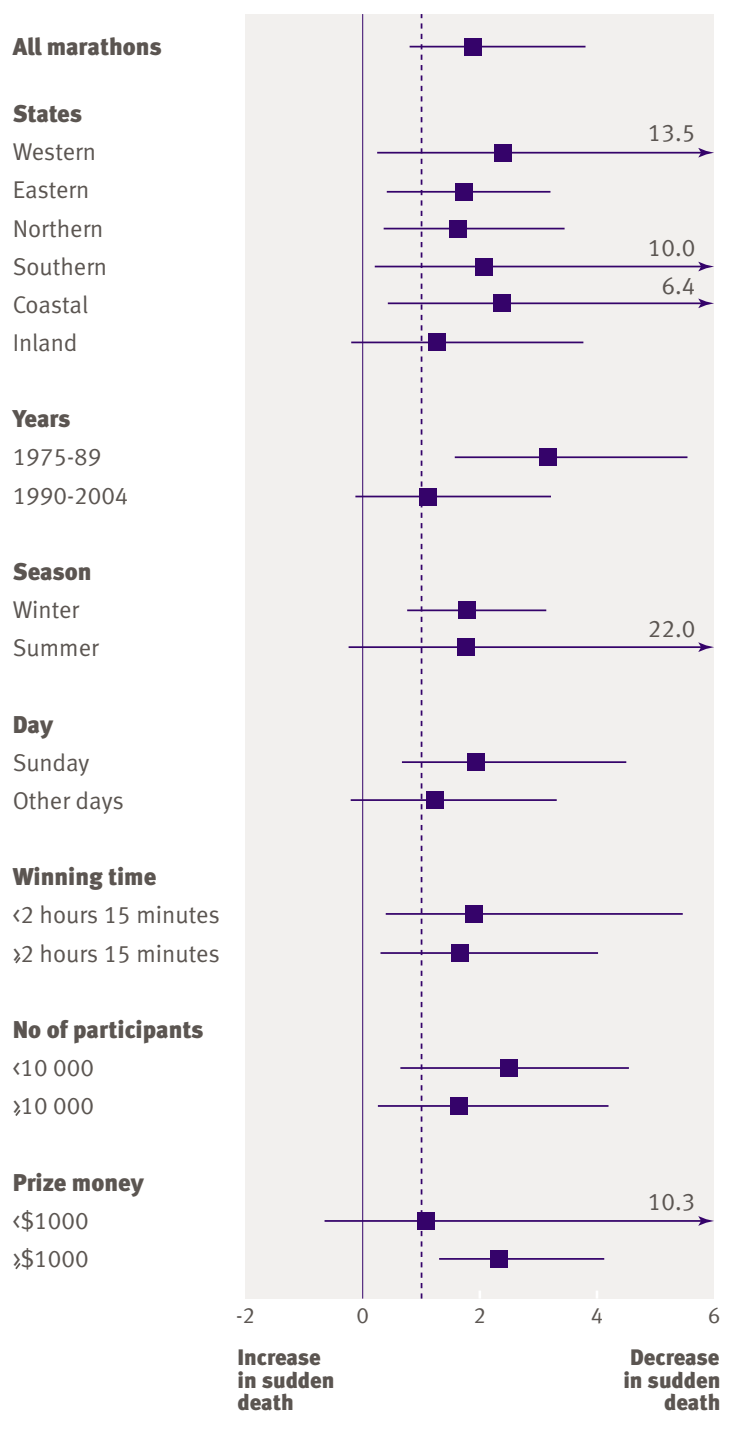

Fig 3 Ratio of crash fatalities prevented to cardiac deaths observed for average marathon. Values above zero indicate a decrease in crash deaths on marathon days relative to control days. Values over one indicate that number of crash deaths averted on marathon days exceeds number of cardiac deaths on marathon days. Full analysis appears at top based on all marathons and all times. $95 \%$ confidence interval calculated from bootstrap techniques. Weekday, winning time, number of participants, and prize money defined by most recent year

crashes that would have otherwise occurred (with comparable demographic profiles of cardiac deaths and crash deaths). The results were consistent in different parts of the country, decades of observation, and objective characteristics of the race. From a public health perspective these data suggest that running a marathon is no more dangerous than typical community activity on US roads.

\section{Societal perspective}

Because we used a retrospective ecological design to study risk our study does not prove that the individuals who die from running a marathon might have been saved from a motor vehicle crash. At the extreme, perhaps the reductions in crash deaths reflect the lives of spectators and uninvolved members of the community saved because of road closures. Previous research, however, shows that those who die in motor vehicle crashes are sometimes young healthy members of society and similar to participants in marathons. ${ }^{25}$ Furthermore, analysis of demographic characteristics showed overlap between the two groups of sudden death identified in our study. Depending on personal lifestyle, therefore, the observed ratio implies that participants in marathons may lower societal risk but may or may not decrease their personal risk.

\section{Individual psychology}

Another limitation of our research is that we evaluated sudden death using numerical data whereas human psychology causes people to focus on some causes of death while neglecting others. ${ }^{26}$ Cardiovascular deaths in athletes are shocking. Identified lives are more salient than statistical lives, thereby slanting community consciousness away from motor vehicle crashes. Bizarre deaths seem more newsworthy than common causes of death, and the different types of sudden death are not portrayed equivalently. Losses loom larger than the corresponding gains, so that a partial reduction of a common cause of death (vehicle crashes) seems no consolation for even a single death in a marathon runner. Moreover, fatalities at sporting events provide a convenient way for some people to rationalise their inactivity.

\section{Beyond marathons}

Our research has many other limitations. The data do not account for sudden cardiac deaths during training or after racing (although the physiological and psychological stress would presumably be smaller than during a marathon). We studied fatalities and not soft tissue injuries or other incidents that are not immediately life threatening. ${ }^{27-30}$ Our study focuses on marathons and not other forms of exercise as the diversity and subtleties of each sport make related questions difficult to tackle from a scientific perspective. The analysis excluded small marathons, yet the pattern suggested that marathons with fewer participants showed a somewhat higher protective association. In addition, our study did not account for the potential enhanced health from regular exercise or how the quality of care at marathon sites might be improved. $^{31}$

\section{Clinical implications}

Clinicians interested in preventing sudden cardiac death may be surprised by the low risk associated with marathon running. The rate we observed was significantly below that reported from research on small samples provoked by signal events $(1 / 50000)^{32-36}$, smaller than the risk of any type of crash associated with driving $42 \mathrm{~km}(1 / 15000)^{37}$; and about the same as the baseline hourly risk of death for a middle aged man..$^{38}$ Our results also imply that the screening that prevailed 


\section{WHAT IS ALREADY KNOWN ON THIS TOPIC}

Running a marathon can lead to sudden death, as

documented 2500 years ago

Such fatalities at sporting events attract broad attention in modern media

\section{WHAT THIS STUDY ADDS}

The absolute risk is much lower than estimated by small studies provoked by signal events

The relative risk is smaller than the risk of a motor vehicle fatality on the same roads during the same time intervals

The final $1.6 \mathrm{~km}$ of the marathon represents less than $5 \%$ of the total distance yet accounts for almost $50 \%$ of the sudden cardiac deaths

for the past 30 years (medical assessment and self selection) yielded participants with a low baseline risk. ${ }^{3940}$ Hence, new technologies proposed for future screening would need to be inexpensive $(<\$ 100(£ 49$, $€ 68)$ per patient) and extremely accurate (specificity $>99 \%$ ) to be cost effective. ${ }^{41} \mathrm{~A}$ healthcare provider with limited resources, therefore, might be better served through enhanced efforts towards resuscitation rather than screening.

\section{Policy relevance}

Our study dispels a popular misconception and thereby also has policy implications. The results highlight the ongoing frequency of road crashes and how brief changes in driving can lead to a measurable reduction in health losses. A greater awareness of this issue might provide some context in the interpretation of widely publicised sports fatalities. The net decrease in sudden deaths we observed may bolster general support for aerobic exercise and temper a few lawsuits that follow from the occasional sudden cardiac death. ${ }^{4243}$ The distribution of cardiac deaths suggests that paramedic staffing for marathons should be planned on the basis of numbers of participants and that the last half of the marathon (and the last $1.6 \mathrm{~km}$ in particular) is the priority for resuscitation resources, ambulance preparedness, and pre-planned departure routes. ${ }^{44}$ The results also indicate that, for participants, the final sprint with sudden cessation may be more dangerous than generally realised.

We thank Fred Brenneman, Trevor Hastie, Daniel Hackam, David Juurlink, Marko Katic, Robert Myers, Lee Ross, Michael Schull, Steven Shumak, Arthur Slutsky, Matthew Stanbrook, and Robert Tibshirani for helpful comments on specific points.

Contributors: Both authors participated in study design, interpretation of results, and approval of the final draft. DAR is guarantor.

Funding: Canada Research Chair in Medical Decision Sciences, the Canadian Institutes of Health Research, the National Institutes of Health Resuscitation Outcomes Consortium, the University of Toronto Summer Scholarship Program, the Patient Safety Service of Sunnybrook Health Sciences Centre, and the PSI Foundation of Ontario.

Competing interests: None declared.

Ethical approval: Research ethics board of Sunnybrook Health Sciences Centre.

Provenance and peer review: Not commissioned; externally peer reviewed.
1 Noakes TD. Heart disease in marathon runners: a review. Med Sci Sports Exerc 1987;19:187-94.

2 Maron BJ, Araujo CG, Thompson PD, Fletcher GF, de Luna AB, Fleg IL, et al. Recommendations for preparticipation screening and the assessment of cardiovascular disease in masters athletes. Circulation 2001;103:327-34.

3 Sedivy R, Bankl HC, Stimpfl T, Bankl H, Kurkciyan I. Sudden, unexpected death of a young marathon runner as a result of bronchial malformation. Mod Pathol 1997:10:247-51.

4 Ratliff NB, Harris KM, Smith SA, Tankh-Johnson M, Gornick CC, Maron BJ. Cardiac arrest in a young marathon runner. Lancet 2002;360:542.

5 Maron BJ. Sudden death in young athletes. N Engl I Med 2003;349:1064-75.

6 Maron BJ, Zipes DP. Introduction: eligibility recommendations for competitive athletes with cardiovascular abnormalities-general considerations. J Am Coll Cardiol 2005;45:1318-21.

7 Saperstein S. Marine who died during marathon here had undiagnosed heart ailment. Washington Post 1986 Nov 4, B1.

8 Manier J, Deardorff J. Marathon death stirs questions. Chicago Tribune 1998 Oct 16; 1.

9 Greenidge J. Runner collapses and dies: 61-year-old Swede succumbs at finish. Boston Globe 1996 April 16; 51

10 Weber B. Two runners who died weren't novices. New York Times 1994 Nov 8; B13.

11 Arnold D. Marathon runner's death still a mystery. Boston Globe 2002 April 19; B3.

12 Wright W. Man's death puts damper on annual event. Honolulu Advertiser 2002 Dec 9; A1

13 Wilson T. Runner's death raises question about safety of marathon Chicago Tribune 2000 Oct 24; 5.

14 Weinreb A. Toronto marathon should be banned. Canada Free Press 2004 Oct 20.

15 Corrado D, Pelliccia A, Bjornstad HH, Vanhees L, Biffi A, Borjesson M, et al. Cardiovascular pre-participation screening of young competitive athletes for prevention of sudden death: proposal for a common European protocol. Eur Heart / 2005;26:516-24.

16 Brody JE. To lower risk of jogging on trail, get off the couch. New York Times 2006 June 20; D7.

17 Reynolds G. Is marathon running too much of a good thing for your heart? New York Times 2006 Dec 7.

18 National Highway Traffic Safety Administration . www.nhtsa.dot.gov

19 Girasek DC. Would society pay more attention to injuries if the injury control community paid more attention to risk communication science? Inj Prev 2006;12:71-3.

20 Wooley PJ. A deadly story we keep missing. Washington Post 2006 Dec 27; A19.

21 World Health Organization. World report on road traffic injury prevention . Geneva: WHO, 2004.

22 Redelmeier DA, Tan SH, Booth GL. The treatment of unrelated disorders in patients with chronic medical diseases. $N$ Engl J Med 1998;338:1516-20.

23 Redelmeier DA, Stewart CL. Driving fatalities on Super Bowl Sunday. N Engl J Med 2003;348:368-9.

24 Redelmeier DA, Stewart CL. Do fatal crashes increase following a Super Bowl telecast? Chance 2004;17:19-24.

25 Evans L. Traffic safety. Bloomfield Hills, MI: Science Serving Society, 2004.

26 Shafir E, ed. Preference, belief, and similarity . Cambridge, MA: M IT Press, 2004.

27 Cerio R, Moody A. The London marathon: 3 years in the running. Arch Emerg Med 1985;2:89-91.

28 Caselli MA, Longobardi SJ. Lower extremity injuries at the New York City marathon. J Am Podiatr Med Assoc 1997;87:34-7.

29 Simons SM, Kennedy RG. Gastrointestinal problems in runners. Curr Sports Med Rep 2004:3:112-6.

30 Sanchez LD, Corwell B, Berkoff D. Medical problems of marathon runners. Am J Emerg Med 2006;24:608-15.

31 Maron BJ. The paradox of exercise. N Engl / Med 2000;343:1409-11.

32 Thompson PD, Funk E), Carleton RA, Sturner WQ. Incidence of death during jogging in Rhode Island from 1975 through 1980. JAMA 1982;247:2535-8.

33 Siscovick DS, Weiss NS, Fletcher RH, Lasky T. The incidence of primary cardiac arrest during vigorous exercise. $N$ Engl J Med 1984:311:874-7.

34 Lemaitre RN, Siscovick DS, Raghunathan TE, Weinmann S, Arbogast P, Lin DY. Leisure-time physical activity and the risk of primary cardiac arrest. Arch Intern Med 1999;159:686-90.

35 Maron BJ, Poliac LC, Roberts WO. Risk of sudden cardiac death associated with marathon running. J Am Coll Cardiol 1996;28:428-31.

36 Roberts WO, Maron BJ. Evidence for decreasing occurrence of sudden cardiac death associated with the marathon. J Am Coll Cardiol 2005;46:1373-4. 
37 US Department of Transportation. Traffic safety facts 2003. Washington, DC: National Highway Traffic Safety Administration, 2005. www-nrd.nhtsa.dot.gov/pdf/nrd-30/NCSA/TSFAnn/ TSF2003F.pdf

38 US Census Bureau. Statistical abstract of the United States 20042005. Washington, DC: Government Printing Office,

2004. www.census.gov/prod/2004pubs/04statab/vitstat.pdf

39 Maron BJ, Araújo CG, Thompson PD, Fletcher GF, de Luna AB, Fleg JL, et al. Recommendations for preparticipation screening and the assessment of cardiovascular disease in masters athletes. Circulation 2001;103:327-34.
40 Maron BJ, Douglas PS, Graham TP, Nishimura RA, Thompson PD. Task force 1: preparticipation screening and diagnosis of cardiovascular disease in athletes. J Am Coll Cardiol 2005;45:1322-6.

41 Hecht HS. Recommendations for preparticipation screening and the assessment of cardiovascular disease in masters athletes. Circulation 2001;104:E58.

42 Mitten MJ. Emerging legal issues in sports medicine: a synthesis, summary, and analysis. St John's L Rev 2002;76:5-86.

43 Saffro v. Elite Racing Inc, (2002), 02 C.D.O.S. 3941.

44 Jaworski CA. Medical concerns of marathons. Curr Sports Med Rep 2005;4:137-43. 